\title{
PENGARUH RHYTHM THERAPY TERHADAP PERKEMBANGAN MOTORIK, SENSORI DAN GEJALA PADA ANAK AUTISM SPECTRUM DISORDER CHILDREN (ASD)
}

\author{
Erna Ariyanti Kurnianingsih, Erayanti Saloko \\ Poltekkes Kemenkes Surakarta Jurusan Okupasi Terapi
}

\begin{abstract}
Background: Music is long known to have therapeutic effect. It can be a mean to improve adaptive behavior, communication, functioning, and understanding of emotion for ASD Children. In form of rhythm therapy, music is mainly used to stimulate rhythm internalization to achieve better focus and more coordinated movements. In addition to its use to obtain non-musical skills, rhythm therapy can also achieve client occupational performance in playing musical instruments. Method: The design of this study is quasi experiment with control group pretest-posttest design. 30 samples of ASD ages 3 -10 years were divided into groups of intervention using rhythm therapy, and control group using occupational therapy standard for 12 weeks. The Test of Gross Motor Development (TGMD), Short Sensory Profile (SSP)and Gilliam Autism Rating Scale (GARS) were administered before and after intervention. Result: The Mann U Whitney result showed TGMD scores showed 0.125 ( $p>0,05)$, SSP scores showed 0,000 ( $p<$ $0,05)$ and GARS scores showed 0,001 ( $p<0,05)$. Conclusion: It can be concluded that there was no effect of rhythm therapy on motor of ASD children. There is an effect of rhythm therapy ob sensory of ASD Children, and there is an effect of rhythm therapy on the symptoms of ASD Children
\end{abstract}

Keyword: Autism, Autism Spectrum Disorder, Music Therapy, Rhythm Therapy, Motor, Sensory, Symptoms.

\section{PENDAHULUAN}

Autisme merupakan disabilitas perkembangan yang kompleks, yang gejalanya mulai nampak pada tiga tahun pertama kehidupan. Gangguan neurologis akibat autisme mempengaruhi fungsi otak sehingga memberikan efek gangguan perkembangan pada anak. Autisme dalam klasifikasi menurut American Psychiatric Association (APA, 2013) dikenal sebagai Autism Spectrum Disorders (ASD).

Anak ASD memiliki beberapa karakteristik yang khas, berupa gangguan sensorik, gangguan koordinasi motorik, dan adanya perilaku stereotype, gangguan komunikasi dan gangguan interaksi sosial (APA, 2013). Prevalensi anak ASD semakin meningkat setiap tahunnya, dengan frekuensi kejadian di Amerika Serikat mencapai $1 \%$ dari keseluruhan populasi. Data terakhir menyebutkan 1: 250 kelahiran memiliki kecenderungan mengalami ASD. Tingginya angka kejadian tersebut menjadikan fenomena yang mengemuka tentang rehabilitasi anak dengan ASD.

Penanganan rehabilitasi pada anak dengan ASD melibatkan berbagai profesi bidang kesehatan dan bidang pendidikan, termasuk okupasi terapi. Menurut Peraturan Menteri Kesehatan Republik 
Indonesia no. 76 tahun 2014 menyebutkan bahwa Okupasi terapis adalah profesi kesehatan yang menjadi bagian pelayanan kesehatan di Indonesia, yang memiliki kompetensi memberikan pelayanan kepada klien baik individu maupun kelompok yang mengalami gangguan fisik dan atau mental, melibatkan penggunaan aktifitas bermakna dan memiliki tujuan terapi yang didesain khusus bagi klien dengan tujuan meningkatkan kemandirian dalam melakukan aktifitas sehari-hari, produktivitas dan pemanfaatan waktu luang (activity of daily living, productivity and leisure) dan partisipasi di dalam masyarakat (Kemenkes, 2014).

Musik sudah lama dikenal memiliki efek terapeutik. Ini dapat menjadi sarana untuk meningkatkan perilaku adaptif, komunikasi, fungsi, dan pemahaman emosi untuk ASD Children. Dalam bentuk terapi ritme, musik terutama digunakan untuk merangsang internalisasi irama untuk mencapai fokus yang lebih baik dan gerakan yang lebih terkoordinasi. Selain penggunaannya untuk memperoleh keterampilan nonmusik, terapi irama juga dapat mencapai kinerja klien dalam memainkan alat musik.

Salah satu metode okupasi terapi yang saat ini sedang berkembang adalah terapi musik, yang lebih spesifik berupa Rhythm therapy. Intervensi okupasi terapi musik berupa Rhythm therapy merupakan penglibatan musik sebagai modalitas dalam proses intervensi. Rhythm, atau lebih dikenal dengan ritme atau irama merupakan komponen dalam musik yang ekuivalen dengan ritme fisiologis manusia, yaitu dapat berupa detak jantung, irama organ dl (American Music Therapy Association, 2010). Dalam sudut pandang okupasional, Rhythm therapy dapat mendukung keterampilan hidup. Selain penggunaannya untuk mendapatkan keterampilan non musik, Rhythm therapy juga dapat mencapai kinerja okupasional klien menjadikan musik sebagai kegiatan leisure.

Oleh karena perkembangan komponen okupasional anak autisme dipengaruhi oleh aktivitas anak dan program rehabilitasi yang diikuti, maka penting untuk mengkaji efek Rhythm therapy terhadap perkembangan sensorik, motorik dan gejala pada anak dengan ASD.

\section{METODE PENELITIAN}

Penelitian ini dilakukan dengan rancangan quasi experiment dengan control group pretest-post test design. Populasi dalam penelitian ini adalah pasien ASD yang memperoleh penanganan okupasi terapi di Gilang Ramadhan Studio Band Surakarta (kelompok perlakuan) dan di Global Therapy Center di Sukoharjo (kelompok kontrol). Pengambilan sampel menggunakan teknik purposive sampling dengan kriteria pasien ASD yang berusia lebih dari tiga tahun, mengikuti Rhythm therapy (untuk kelompok perlakuan) dan yang mengikutiintervensi okupasi terapi standar (untuk kelompok kontrol) dan bersedia menjadi responden penelitian.

Data penelitian diukur dengan Test of Gross Motor Development - 2nd edition (TGMD),The Short Sensory Profile (SSP),Gilliam Autism Rating Scale - 2nd edition (GARS).

\section{HASIL PENELITIAN}

Berdasarkan perkembangan motorik responden dapat dilihat pada tabel 1 dapat diketahui bahwa rerata 
perubahan perkembangan motorik responden kelompok perlakuan adalah 4,87 .

Tabel 1. Tabel Perkembangan Motorik Responden Sebelum dan Setelah

\begin{tabular}{|c|c|c|c|}
\hline No ${ }^{\mathrm{N}}$ & $\begin{array}{l}\text { Nilai Perkembangan } \\
\text { Motorik Sebelum } \\
\text { Perlakuan }\end{array}$ & $\begin{array}{c}\text { Nilai } \\
\text { Perkembangan } \\
\text { Motorik Setelah } \\
\text { Perlakuan } \\
\end{array}$ & Delta \\
\hline 1 & 46 & 51 & 5 \\
\hline 2 & 58 & 70 & 12 \\
\hline 3 & 46 & 49 & 3 \\
\hline 4 & 82 & 84 & 2 \\
\hline 5 & 49 & 51 & 2 \\
\hline 6 & 46 & 49 & 3 \\
\hline 7 & 61 & 70 & 9 \\
\hline 8 & 49 & 52 & 3 \\
\hline 9 & 58 & 64 & 6 \\
\hline 10 & 67 & 70 & 3 \\
\hline 11 & 59 & 67 & 8 \\
\hline 12 & 68 & 75 & 7 \\
\hline 13 & 73 & 77 & 4 \\
\hline 14 & 64 & 68 & 4 \\
\hline 15 & 80 & 82 & 2 \\
\hline Rerata & 60,4 & 65,27 & 4,87 \\
\hline
\end{tabular}

Perkembangan motorik responden pada kelompok kontrol dapat dilihat pada tabel 2 berikut. Berdasarkan tabel 2 dapat dilihat bahwa rerata perubahan perkembangan motorik responden kelompok perlakuan adalah 3,33.

Tabel 2. Tabel Perkembangan Motorik Responden di Awal dan Akhir Penelitian Pada Kelompok Kontrol

\begin{tabular}{cccc}
\hline No & $\begin{array}{c}\text { Nilai } \\
\text { Perkembangan } \\
\text { Motorik Awal }\end{array}$ & $\begin{array}{c}\text { Nilai } \\
\text { Perkembangan } \\
\text { Motorik Akhir }\end{array}$ & Delta \\
\hline 1 & 43 & 46 & 3 \\
2 & 36 & 43 & 7 \\
3 & 20 & 23 & 3 \\
4 & 32 & 36 & 4 \\
5 & 24 & 27 & 3 \\
6 & 45 & 51 & 6 \\
7 & 45 & 48 & 3
\end{tabular}

\begin{tabular}{cccc}
8 & 45 & 47 & 2 \\
9 & 42 & 44 & 2 \\
10 & 46 & 49 & 3 \\
11 & 46 & 47 & 1 \\
12 & 76 & 78 & 2 \\
13 & 45 & 51 & 6 \\
14 & 45 & 48 & 3 \\
15 & 45 & 47 & 2 \\
\hline Rerata & 42,33 & 45,67 & 3,33 \\
\hline \multicolumn{4}{r}{ Gambaran perkembangan sensorik }
\end{tabular}
responden pada kelompok perlakuan dan kelompok kontrol dapat diketahui dari tabel 3 dan 4 berikut. Berdasarkan tabel 3 dapat diketahui perubahan perkembangan sensorik responden kelompok perlakuan bahwa perubahan perkembangan sensorik responden kelompok perlakuan sebelum dan setelah perlakuan adalah 32,4.

Tabel 3. Tabel Perkembangan Sensorik Responden Sebelum dan Setelah Diberikan Intervensi Pada Kelompok Perlakuan

\begin{tabular}{cccc}
\hline No & $\begin{array}{c}\text { Nilai } \\
\text { Perkembangan } \\
\text { Sensorik Sebelum } \\
\text { Perlakuan }\end{array}$ & $\begin{array}{c}\text { Penserik Setai } \\
\text { Perlakuan }\end{array}$ & Delta \\
\hline 1 & 122 & 165 & 43 \\
2 & 93 & 154 & 61 \\
3 & 117 & 136 & 19 \\
4 & 102 & 140 & 38 \\
5 & 125 & 150 & 25 \\
6 & 110 & 150 & 40 \\
7 & 108 & 156 & 48 \\
8 & 99 & 126 & 27 \\
9 & 94 & 138 & 44 \\
10 & 87 & 114 & 27 \\
11 & 102 & 131 & 29 \\
12 & 123 & 137 & 14 \\
13 & 97 & 119 & 22 \\
14 & 106 & 132 & 26 \\
15 & 112 & 135 & 23 \\
\hline Rerata & 106,5 & 138,9 & 32,4 \\
\hline \multicolumn{5}{c}{ Perkembangan sensorik responden } \\
pada & kelompok kontrol yang diukur di \\
awal dan akhir penelitian dapat dilihat \\
pada & tabel 4 berikut ini. Tabel 4
\end{tabular}


menunjukkan bahwa perubahan perkembangan sensorik responden kelompok kontrol adalah 15.

Tabel 4. Perkembangan Sensorik Responden Kelompok Kontrol Yang diukur di awal dan akhir penelitian

\begin{tabular}{|c|c|c|c|}
\hline No & $\begin{array}{l}\text { Nilai Perkembangan } \\
\text { Sensorik di Awal }\end{array}$ & $\begin{array}{c}\text { Nilai } \\
\text { Perkembangan } \\
\text { Sensorik diakhir }\end{array}$ & Delta \\
\hline 1 & 103 & 116 & 13 \\
\hline 2 & 109 & 119 & 10 \\
\hline 3 & 84 & 99 & 15 \\
\hline 4 & 102 & 130 & 28 \\
\hline 5 & 90 & 112 & 22 \\
\hline 6 & 98 & 119 & 21 \\
\hline 7 & 105 & 116 & 11 \\
\hline 8 & 104 & 118 & 14 \\
\hline 9 & 111 & 123 & 12 \\
\hline 10 & 124 & 133 & 9 \\
\hline 11 & 128 & 136 & 8 \\
\hline 12 & 136 & 157 & 21 \\
\hline 13 & 98 & 119 & 21 \\
\hline 14 & 105 & 116 & 11 \\
\hline 15 & 100 & 112 & 12 \\
\hline Rerata & 106,47 & 121,67 & 15,2 \\
\hline
\end{tabular}

sebelum dan setelah perlakuan dapat dilihat pada tabel 5 berikut ini. Tabel 5 menunjukkan bahwa perubahan gejala yang terjadi sebelum dan setelah perlakuan sebesar 19,33.

Tabel 5. Gejala ASD Responden Kelompok Perlakuan Sebelum dan Setelah Perlakuan

\begin{tabular}{cccc}
\hline No & $\begin{array}{c}\text { Nilai } \\
\text { Perkembangan } \\
\text { Gejala Sebelum } \\
\text { Perlakuan }\end{array}$ & $\begin{array}{c}\text { Nilai } \\
\text { Perkembangan } \\
\text { Gejala Setelah } \\
\text { Perlakuan }\end{array}$ & Delta \\
\hline 1 & 130 & 115 & 15 \\
2 & 115 & 100 & 15 \\
3 & 95 & 85 & 10 \\
4 & 125 & 120 & 5 \\
5 & 110 & 80 & 30 \\
6 & 110 & 85 & 25 \\
7 & 120 & 100 & 20
\end{tabular}

\begin{tabular}{cccc}
8 & 120 & 110 & 10 \\
9 & 120 & 90 & 30 \\
10 & 120 & 100 & 20 \\
11 & 125 & 105 & 20 \\
12 & 110 & 105 & 5 \\
13 & 125 & 100 & 25 \\
14 & 110 & 80 & 30 \\
15 & 130 & 100 & 30 \\
\hline Rerata & 117,67 & 98,33 & 19,33 \\
\hline \multicolumn{5}{c}{ Berikut merupakan perubahan } \\
gejala yang dijumpai pada responden \\
kelompok kontroldi awal dan akhir \\
penelitian. Berdasarkan table 6 dapat \\
diketahui bahwa perubahan gejala pada \\
responden kelompok kontrol adalah 7,67.
\end{tabular}

Tabel 6. Perubahan Gejala pada Responden Kelompok Kontrol di Awal dan Akhir Penelitian

\begin{tabular}{|c|c|c|c|}
\hline No & $\begin{array}{l}\text { Nilai Gejala } \\
\text { ASD di Awal }\end{array}$ & ASD di Awal ASD diakhir & Delta \\
\hline 1 & 120 & 110 & 10 \\
\hline 2 & 120 & 115 & 5 \\
\hline 3 & 135 & 130 & 5 \\
\hline 4 & 135 & 125 & 10 \\
\hline 5 & 130 & 120 & 10 \\
\hline 6 & 130 & 125 & 5 \\
\hline 7 & 120 & 115 & 5 \\
\hline 8 & 130 & 125 & 5 \\
\hline 9 & 130 & 125 & 5 \\
\hline 10 & 110 & 100 & 10 \\
\hline 11 & 115 & 95 & 20 \\
\hline 12 & 110 & 115 & -5 \\
\hline 13 & 130 & 125 & 5 \\
\hline 14 & 120 & 115 & 5 \\
\hline 15 & 120 & 100 & 20 \\
\hline Rerata & 123,67 & 116 & 7,67 \\
\hline $\begin{array}{l}\text { motori } \\
\text { dengan } \\
\text { terdapa } \\
\text { terhada } \\
\text { tersebu } \\
\text { kompo } \\
\text { signifil }\end{array}$ & $\begin{array}{l}\text { Berdasarka } \\
\text { diketahui b } \\
\text { ik nilai signi } \\
\text { n demikiar } \\
\text { at pengaru } \\
\text { ap motorik } \\
\text { ut juga } \\
\text { onen senso } \\
\text { kansi } 0,00\end{array}$ & $\begin{array}{l}\text { an tabel } 7 . \\
\text { oahwa pada } \\
\text { ifikasi } 0,125 \\
n \quad \text { disimpul } \\
\text { h rhyth } \\
\text { anak ASD. } \\
\text { menunjukka } \\
\text { rik memp } \\
0 \quad(\mathrm{p}<0,0\end{array}$ & $\begin{array}{l}\text { bawah ini } \\
\text { omponen } \\
\mathrm{p}>0,05) \\
\text { a tidak } \\
\text { therapy } \\
\text { ada tabel } \\
\text { bahwa } \\
\text { yai nilai } \\
\text { artinya }\end{array}$ \\
\hline
\end{tabular}


terdapat pengaruh rhythm therapy terhadap komponen sensorik anak ASD. Sedangkan komponen gejala ASD mempunyai nilai signifikansi $0,001 \quad(\mathrm{p}<$ $0,05)$ sehingga dapat disimpulkan bahwa terdapat pengaruh rhythm therapy terhadap gejala anak ASD.

Tabel 7 . Hasil Uji Mann Whitney Delta Rerata Perkembangan Motorik, Sensorik Dan Gejala ASD Pada Responden Kelompok Intervensi Dan Kelompok Kontrol

\begin{tabular}{lllcll}
\hline $\begin{array}{l}\text { Delta } \\
\text { Intervensi }\end{array}$ & $\begin{array}{l}\text { Mann- } \\
\text { whitney } \\
\mathrm{U}\end{array}$ & $\begin{array}{l}\text { Wilcoxon } \\
\mathrm{W}\end{array}$ & $\mathrm{Z}$ & $\begin{array}{l}\text { Asymp } \\
\text {.sig.(2- } \\
\text { tailed) }\end{array}$ & $\begin{array}{l}\text { Exact } \\
\text { sig. } \\
(2 *(1-\end{array}$ \\
$\begin{array}{l}\text { tailed } \\
\text { sig.) })\end{array}$ \\
\hline Motorik & 76,500 & 196,500 & $-1,533$ &, 125 &, $137^{\mathrm{b}}$ \\
Sensorik & 18,000 & 138,000 & $-3,924$ &, 000 &, $000^{\mathrm{b}}$ \\
Gejala & 35,000 & 155,000 & $-3,301$ &, 001 &, $001^{\mathrm{b}}$ \\
\hline
\end{tabular}

\section{PEMBAHASAN}

Musik telah lama diketahui memiliki efek terapetik (Hall \& Smith, 2018) Okupasi terapis, terapis wicara, psikologis telah mengadopsi penggunaan musik pada berbagai kondisi. Okupasi terapis menggunakan musik untuk persiapan aktivitas terapetik dengan didasari asumsi bahwa input sensori melalui auditori dan vestibular dapat membuat anak tenang dan dikelola dengan baik. (Ayres 1979; Frick \& Hacker, 2001 dalam Hall \& Smith, 2018)

Srinivan \& Bhat (2013) dalam artikel berjudul "A review of Music and Movement Therapies for Children with autism + Embodied Interventions for Multisystem Development" menyebutkan bahwa musik dan movement therapy merupakan intervensi klinis yang kuat. Terapi musik digunakan pada kurang lebih $12 \%$ dari keseluruhan intervensi terhadap kasus ASD dan $45 \%$ dari keseluruhan intervensi alternatif yang digunakan pada setting sekolah.
Menariknya, efek dari musik terapi terhadap performance motorik dan motor stereotypes tidak pernah di lakukan uji penelitian, Hasil penelitian ini menunjukkan bahwa :

1. Tidak Terdapat pengaruh Rhythm Therapy terhadap perkembangan motorik anak ASD. Pada komponen motorik diperoleh nilai signifikasi $0,125(\mathrm{p}>0,05)$ sehingga dapat disimpulkan bahwa tidak terdapat pengaruh rhythm therapy terhadap motorik anak ASD. Efek rhythm therapy terhadap motorik sebenarnya telah menjadi asumsi banyak peneliti, karena gerakan tubuh yang ritmis seperti bertepuk tangan, atau memukul alat musik menyediakan kesempatan yang signifikan untuk memfasilitasi keterampilan motorik. Pola temporal yang terdapat dalam ritme musik menstimulasi tubuh untuk menyelaraskan gerakan tubuhnya dapat meningkatkan koordinasi pada anak. (RodriguesFornells et al., 2012, dalam Srinivan and Bhat, 2013). Namun sejauh ini belum terdapat studi tentang efek musik terhadap keterampilan gerak pada anak ASD (Srinivan \& Bhat, 2013). Hal tersebut tidak sesuai dengan pendapat La Gasse \&Hardy (2013) yang menyatakan bahwa rhythmic cueing memfasilitasi perbaikan motoric pada orang individu dengan gangguan neurologis termasuk autism. Perbaikan motoric pada anak ASD dalam penelitian ini dapat dijelaskan sesuai pendapat Hilton et al seperti dikutip oleh La Gasse \& Hardy (2013) menyatakan bahwa $83 \%$ anak ASD mempunyai skor motoric minimal satu level di bawah standard deviasi populasi, dan 
anak dengan severe autism mempunyai impairmen yang lebih banyak. Sedangkan Ghaziuddin \& Buttler; Dziuh et al; Ming et al; David et al seperti dituliskan oleh La Gasse \& Hardy (2013) menyatakan bahwa 80-90 \% anak ASD mempunyai abnormalitas motorik dengan tingkat tertentu.

2. Terdapat pengaruh Rhythm Therapy pada perkembangan sensorik anak ASD. Hasil pengolahan data menunjukkan bahwa pada komponen sensorik diperoleh nilai signifikansi $0,000$ ( $p<0,05)$ dengan demikian dapat disimpulkan bahwa terdapat pengaruh rhythm therapy terhadap komponen sensorik anak ASD. Hal ini sesuai dengan pendapat yang menyebutkan bahwa okupasi terapis menggunakan musik untuk persiapan aktivitas terapetik dengan didasari asumsi bahwa input sensori melalui auditori dan vestibular dapat membuat anak tenang dan dikelola dengan baik (Hall \& Smith, 2018). Pelaksanaan rhythm therapy sesuai dengan modul, memberikan input sensori melalui auditori, vestibular dan proprioseptif.

3. Terdapat pengaruh rhythm therapy terhadap perubahan gejala anak ASD. Pada pengolahan data diperoleh bahwa komponen gejala ASD mempunyai nilai signifikansi 0,001 $(\mathrm{p}<0,05)$ sehingga dapat disimpulkan bahwa terdapat pengaruh rhythm therapy terhadap gejala ASD. Hal ini didukung oleh penelitian musik terapi dengan menggunakan metode Tomatis pada penelitian NeysmithRoy (2001) menemukan bahwa 3 dari 6 anak dengan gejala ASD berat mengalami perbaikan perilaku.
Setelah diintervensi menggunakan Tomatis, satu anak tidak lagi memiliki diganosis autism, 2 anak menunjukan perubahan menjadi autisme ringan, dan 3 anak menunjukkan gejala ASD berat. Dengan demikian dapat disimpulkan bahwa musik rhythm therapy berpengaruh terhadap penurunan gejala ASD.

\section{KESIMPULAN DAN SARAN}

Berdasarkan hasil penelitian dapat disimpulkan bahwa tidak terdapatpengaruh rhythm therapy terhadap perkembangan motorik anak ASD karena pada komponen motorik diperoleh nilai signifikansi 0,125 yang berarti $p>0,05$. Sedangkan pada komponen sensorik dan gejala, menunjukkan nilai signifikansi masingmasing kurang dari 0,05. Sehingga dapat disimpulkan bahwa terdapat pengaruh rhythm therapy terhadap perkembangan sensorik dan perubahan gejala anak ASD. Hasil penelitian ini menunjukkan bahwa rhythm therapy berpengaruh terhadap perkembangan sensorik dan perubahan gejala pada anak ASD ,akan tetapi tidak berpengaruh terhadap komponen motorik anak ASD. Penelitian ini masih memiliki beberapa keterbatasan, sehingga bagi penelitian mendatang perlu dilakukan kontrol beberapa variabel yang kemungkinan dapat mempengaruhi hasil penelitian ini, seperti pengendalian intervensi lain yang diberikan pada saat yang bersamaan.

\section{DAFTAR RUJUKAN}

American Music Therapy Association (2010). Autism Spectrum Disorders: music therapy research and evidence based 
practice support. Maryland: Silver Spring

American Psychiatric Association (2015). Diagnostic and statistical manual of mental disorders -5 edition. London : American Psychiatric Publishing

British Association for Music Therapy( 2011). Music therapy for people on the autistic spectrum. London : White Lion

Berger, D.S, (2002). Music therapy, sensory integration and the autistic child

Dahlan, M. S., (2011). Statistik untuk kedokteran dan kesehatan Edisi 5. Jakarta, Salemba Medika.

Guy, J \& Neve, A (2005). Music therapy $\&$ autism spectrum disorders. San Diego: MTCCA

Hadinoto, W.(2006). Aspek neurologik autistic spectrum disorder. New York: Lange

Kementerian Kesehatan Republik Indonesia. (2014). Peraturan menteri kesehatan nomor 76 tahun 2014 tentang standar pelayanan okupasi terapi. Kementerian Kesehatan Republik Indonesia.

La Gasse, b.a., \& Hardy, M.W. (2013). Rhythm, movement, and autism: using rhythmic rehabilitation research as a model for autism. Frontiers in Integrative Neuroscience. 7(19). 1-9.

Murti, B. (1996). Penerapan metode statistik non parametrik dalam ilmu - ilmu kesehatan. Jakarta : Gramedia Pustaka Utama

Neysmith-Roy JM (2001), the tomatis method with severely autistic boys: individual case studies of behavioral changes. South African journal of Psychology, March 2001

Hall \& Smith., (2018) Sound Therapy: An experimental study with autistic children

Saharso, D.( 2006). Autistic Spectrum Disorder : diagnosis dan tatalaksana. FK Unair RSU dr. Soetomo, Surabaya

Sugiyono. (2004). Statistika untuk penelitian. Bandung : Alfabeta.

Smith, J.C., \& O'brien (2001). Occupational therapy for children. Elsevier Health Science

Srinivan S.M.\& Bhat, A.N (2013), A review of "music and movement" therapies for children with autism: embodied interventions for multisystem development. Frontiers in Integrative Neuroscience, April 2013 Volume 7

World Health Organization Autism Spectrum Disorders: Key facts. http://www.who.int/newsroom/fact-sheets/detail/autismspectrum-disordersl accessed in July 2018

Willard H.S; Spackman C.S; Neistadt M.E; Crepeau E.B (1998). Willard and Spackman's Occupational Therapy. Philladelphia : Lippincott William and Wilkins 